\title{
Validity and Reliability of the Turkish Version of Generalized Anxiety Disorder Scale-Revised
}

\author{
Anıl Gündüz ${ }^{1}$, İbrahim Gündoğmuş ${ }^{\circledR} \bowtie$, Sencan Sertçelik ${ }^{3}$, Betül Hacer Engin ${ }^{4}$, Aysel İşler ${ }^{5}$, \\ Alişan Burak Yaşar ${ }^{6}$, Hatice Gönül ${ }^{3}$, Arif Çipil ${ }^{7}$, and Elvan Başak Usta Gündüz ${ }^{8}$ \\ ${ }^{1}$ Department of Clinical Psychology, İstanbul Kent University, İstanbul,Turkey \\ 2Department of Psychiatry, TC Ministy of Health, Kırıkkale Yüksek İhtisas Hospital, Kırıkkale, Turkey \\ ${ }^{3}$ Department of Psychiatry, Haydarpaşa Numune Training and Research Hospital, İstanbul,Turkey \\ ${ }^{4}$ Kim Psychological Counselling Center, İstanbul, Turkey \\ ${ }^{5}$ UNHCR (United Nations High Commissioner for Refugees), İstanbul, Turkey \\ ${ }^{6}$ Department of Clinical Psychology, İstanbul Gelişim University, İstanbul, Turkey \\ ${ }^{7}$ Private Practice, İstanbul, Turkey \\ ${ }^{8}$ Department of Child and Adolescent Psychiatry, Medeniyet Üniversitesi Göztepe Eğitim Ve Araştırma Hastanesi, İstanbul,Turkey
}

Objective This study aims to assess the psychometric values of the Generalized Anxiety Disorder Scale-Revised (GADS-R) which measures the intensity and duration of worry, various coping and avoidance strategies to cope with worrying, and positive and negative metacognitive beliefs about worrying.

Methods 114 patients with generalized anxiety disorder and 198 healthy controls were included in the study. These patients were diagnosed according to DSM-IV TR, and the primary diagnosis of the patients was generalized anxiety disorder which was confirmed via SCID I and II, subsequently. Sociodemographic form, GADS-R total and subscale scores, and Meta-Cognitions Questionnaire-30 (MCQ30), Beck Depression Inventory (BDI), Beck Anxiety Inventory (BAI), Generalized Anxiety Disorder-7 Scale (GAD-7), and Penn State Worry Questionnaire (PSWQ) were used to assess validity, reliability and cut-off point.

Results GADS-R total and subscale scores and MCQ-30, BDI, BAI, GAD-7, and PSWQ were found to be statistically higher in the patients with GAD compared to a healthy control group. GADS-R has five factors and showed relatively acceptable sensitivity and specificity for detecting anxiety disorders at a cut-off point of 1188 .

Conclusion The GADS-R is a valid and reliable scale that can be used in the Turkish population as an assessment tool.

Psychiatry Investig 2021;18(10):949-957

Keywords Validity; Reliability; Generalized Anxiety Disorder; Generalized Anxiety Disorder Scale-Revised; Worry; Metacognition.

\section{INTRODUCTION}

Generalized Anxiety Disorder (GAD) is described as significant anxiety, fear, and worry about a whole range of events, situations, or activities. Worry is found uncontrollable, and at least three symptoms from restlessness or feeling keyed up or edgy, getting easily fatigued and irritated, concentration problems or empty mind, muscle tension, and sleep disturbance

Received: May 21, 2021 Revised: June 24, 2021

Accepted: August 1, 2021

$\triangle$ Correspondence: İbrahim Gündoğmuş, MD

Department of Psychiatry, TC Ministy of Health, Kırıkkale Yüksek İhtisas Hospital, Bağlarbaşı, Ahmet Ay Caddesi, 71300 Merkez/Kırıkkale, Turkey Tel: +905455870575, E-mail: dribrahim06@gmail.com

(a) This is an Open Access article distributed under the terms of the Creative Commons Attribution Non-Commercial License (https://creativecommons.org/licenses/bync/4.0) which permits unrestricted non-commercial use, distribution, and reproduction in any medium, provided the original work is properly cited. should accompany anxiety and worry which cause impairment in relevant areas of the functioning and cause distress. ${ }^{1}$ Prevalence rates of $\mathrm{GAD}$ range between $8 \%-13.7 \%$. $^{2}$ Although the significant emotional problems and disability were present in $\mathrm{GAD}$, the correct diagnosis was remarkably lower which results in GAD remains poorly recognized and inadequately treated by mental health professionals. ${ }^{3}$

According to the metacognitive model of GAD, patients hold beliefs named "positive metacognitive beliefs" which are about the effectiveness of worrying while dealing with the perceived threat and "negative metacognitive beliefs" which are about uncontrollability and the dangerous consequences of worrying such as physical and psychological harm. ${ }^{4}$ Furthermore, these dysfunctional metacognitions lead to continuous backfiring mental and behavioral coping strategies which are named Cognitive Attentional Syndrome (CAS). ${ }^{4}$ Positive 
metacognitive beliefs initiate CAS, and negative metacognitive beliefs maintain the CAS. ${ }^{5} \mathrm{CAS}$ consists of worry/rumination, threat monitoring, self-focused attention and unhelpful coping strategies such as avoidance, reassurance-seeking, selfmedication, alcohol/substance use and thought suppression as a means of controlling or avoiding worry and stress in response to undesirable internal events. ${ }^{6}$ These strategies reinforce the uncontrollability metacognition and feed the catastrophic thinking style as worrying and coping through CAS which maintains threat-focused processing and prevents to implement new information. ${ }^{7,8}$

Additionally, negative beliefs about worrying regarding uncontrollability and dangerousness lead to worries about worry and anxiety are named "meta-worry" which increases and extends the anxiety symptoms. The individual engages in CAS such as thought-control strategies and different behaviors to decrease worry and its possible dangerous consequences (meta-worry), yet these strategies increase the engagement to negative internal triggers so maintains dysfunctional metacognitive beliefs regarding the loss of control. ${ }^{4}$

There are increasing numbers of research that investigate the relationship between GAD and metacognitions. For instance, the intensity and frequency of worrying in distinguishing GAD from other anxiety disorders, ${ }^{9}$ the relationship between metacognitive beliefs, the tendency to pathological worry, and obsessive-compulsive symptoms are some examples of empirical evidence. $^{10}$

Valid and reliable scales that are used in measuring the severity of worry, anxiety, and metacognitions that are frequently used and preferred in Turkey are Penn State Worry Questionnaire (PSWQ), ${ }^{11}$ Beck Anxiety Inventory (BAI), ${ }^{12}$ The Metacognitions Questionnaire-30 (MCQ-30), ${ }^{13}$ and Generalized Anxiety Disorder-7 (GAD-7) scale. ${ }^{14}$ Although these are very good at measuring levels of worry, anxiety, or metacognitions, yet none of these scales measure the level of the worry, anxiety, metacognitions, and coping strategies at the same time and none of them measures levels of coping strategies and avoided situations. For the reason mentioned above, a scale that measures the intensity and duration of worry, levels of coping strategies, and avoided situations to cope with worry, positive and negative metacognitive beliefs about worrying is essential in the field.

The Generalized Anxiety Disorder Scale-Revised (GADS$\mathrm{R})$ examines the negative and positive metacognitive beliefs and impressions of the types of behaviors used to avoid worry and danger, which can be subtle in GAD. GADS-R might fill this absence of measuring worry, anxiety, metacognitions, avoidance, and coping strategies at once. The purpose of this study is to demonstrate the validity and reliability of the Turkish GADS-R scale.

\section{METHODS}

\section{Subjects}

The GAD patients included in the study consisted of consecutive voluntary patients who applied to the psychiatry clinic of Haydarpaşa Numune Training and Research Hospital between May 2018 and January 2019. These patients were diagnosed according to DSM-IV diagnostic criteria, and the primary diagnosis of the patients was generalized anxiety disorder, which was confirmed via SCID I and II, subsequently. The healthy control group consisted of volunteers who were admitted to other clinics of the hospital and did not have psychopathology which was assessed with SCID-1 and SCID-II. Criteria for recruitment were; being between 18-65 years old, knowing how to read and write, having enough cognitive capacity to understand the questionnaires and to do an interview, and being a volunteer for participation. Those with intellectual disability, a comorbid psychotic disorder, or a severe physical illness, personality disorder, and diagnosis other than GAD were not included in the study or SCID evaluation. 24 participants were excluded from the study because they had a comorbid psychiatric diagnosis. In addition, 35 participants were excluded from the study because they did not fulfill the requirements of the study and filled the forms incompletely. In conclusion, 114 patients with generalized anxiety disorder and 198 healthy controls were included in the study.

Necessary permissions were taken from the developers of the scale for the validity and reliability study of the Turkish version of the GADS-R. A local ethics committee was granted for the study with protocol number 09.2018.351 in May 2018, and the rights of the patients were protected according to the Helsinki Declaration.

\section{Study design}

First, GADS-R has been translated into Turkish by a psychiatrist who is an expert in the field and speaks native English. The Turkish text was translated back into English by another psychiatrist and compared with the original text. The latter English version was translated into Turkish for the second time and concluded to the final Turkish version. A preliminary study was carried out in a small group of patients to control the language structure and coherence of the scale. Due to no negative feedback from the preliminary study, the validity and reliability study was conducted.

The participants were informed about the purpose and methodology of the study, and written consent were taken before the interview and applying scales. First, SCID-1 and SCID-2 were applied. Afterward, the volunteers were asked to fill the socio-demographic form, the GADS-R Turkish version, the MCQ-30, the Beck Depression Inventory (BDI), the 
BAI, the GAD-7 Scale, and the PSWQ.

\section{Data collection tools}

Socio-demographic form; was developed by the researchers to collect information regarding socio-demographic data such as age, sex, marital status, level of education, psychiatric and medical history, alcohol and substance use.

GADS-R was developed by Wells in 2009 to examine the negative and positive metacognitive beliefs about the worry, the level of and the time engaged with the worry, the types of behaviors used to cope and avoid worry and danger. ${ }^{15}$ The scale consists of 28 items, the first 2 of which assess the severity and frequency of worry. The next nine items assess the frequency of the coping strategies to prevent, and the next five items assess avoidance from worry. The next six items include the level of negative metacognitive beliefs, and finally, the last six items include the level of positive metacognitive beliefs of individuals about worry and coping strategies. The first 16 items are measured on a 0-8 Likert type measure, and the last 12 items are Likert's type measures evaluated with a scoring system between 0-100. In order to calculate the total score, the scoring of the first 16 items was converted to scoring between 0 and 100 (The scores of the first 16 items were increased to 12.5 times). Then 28 items were collected to form a total score. To the best of our knowledge, GADS-R has no other validity reliability studies.

MCQ-30 was developed to assess the metacognitive beliefs, judgments, and monitoring tendencies by Wells and Cartwright-Hatton in 2004. ${ }^{16}$ The scale consists of 30 items and is answered on a 4-point Likert-type rating scale. The scale consists of 5 subscales; positive beliefs about worry, negative beliefs about thoughts concerning uncontrollability and danger, cognitive confidence, beliefs about the need to control thoughts, and cognitive self-consciousness. The range of points that can be taken from the scale ranges from 30-120. The increase in the total score of the scale is indicative of increased pathologic metacognitive activity, and there is no cut-off value. Reliability of Turkish validity was made by Tosun and Irak. ${ }^{13}$ The Cronbach Alpha reliability coefficient was 0.86 .

$\mathrm{BDI}$ was used to measure the level of depressive symptoms. The scale was developed to measure physical, emotional, cognitive, and motivational manifestations of depression. The scale consisting of 21 items is a 4-point Likert type with 0-3 scoring. ${ }^{17}$ The Turkish validity and reliability study was conducted in 1998. ${ }^{12}$

BAI was used to measure the level of participants' anxiety symptoms. The scale was developed to measure the severity of the anxiety experienced by the individual. It consists of 21 items and is a measure of 4 Likert type between 0-3 Beck et al. ${ }^{18}$ The Turkish validity and reliability study was conducted in $1993 .^{19}$

GAD-7 Scale is a self-reported scale that determines the frequency of anxiety symptoms experienced within the last two weeks. The high scores indicate the severity of the anxiety experienced by the individual. Cut off values of 5,10 , and 15 were determined for mild, moderate, and severe anxiety respectively. It consists of 7 items and is a measure of 4 Likert types between $0-3 .^{20}$ The validity and reliability of the Turkish version were made in 2013. ${ }^{14}$

PSWQ was used to determine the level of pathological anxiety levels of patients. The scale was developed to determine extreme, permanent, and uncontrollable pathological anxiety levels. It consists of 16 items and is a measure of 5 Likert type between $1-5 .{ }^{21}$ The validity and reliability of the Turkish version were made 2008. ${ }^{11}$

\section{Statistical analysis}

Data were statistically analyzed by using Statistical Package for the Social Sciences (SPSS) version 20.0 (IBM Corp., Armonk, NY, USA). The socio-demographic and clinical characteristics of the participants, the numerical variables were examined and presented as the mean and categorical variables as a percentage. Chi-square test was used to compare categorical data between the patient and control groups, and Student$\mathrm{t}$ test was used to compare numerical data.

For reliability; the internal consistency of the GADS-R was tested using Cronbach's Alpha. The internal consistency was assessed for the total population sample and five subgroups. Mean scores, patients-control comparison for each item, Cronbach Alpha if item deleted, and item-total correlations were calculated to investigate item characteristics of the GADS-R.

The factor structure of the GADS-R was examined using the Explanatory Factor Analysis with a Varimax rotation method. The dimensionality of the GADS-R, suggested by the original version, was assessed with factor analysis. The suitability of the data for factor analysis was assessed as follows; 1) Kaiser-Meyer-Olkin (KMO) value should be above $0.60,2$ ) should assess to a statistically significant Bartlett's test for sphericity and $\mathrm{p} \leq$ $0.05,3$ ) should be the presence of many coefficients of above 0.30 in the correlation matrix, and 4) should be commonalities above 0.30 .

To determine the overlaps and validity of the GADS-R, the relationships between MCQ-30, BDI, BAI, GAD-7, PSWQ scales were assessed with Pearson correlation coefficient. The ROC curve was calculated to the cut-off value. $\leq 0.05$ was considered statistically significant. Correlation coefficients greater than 0.30 were accepted adequate. 


\section{RESULTS}

The socio-demographic data of participants are presented in Table 1. 185 (59.3\%) of the participants were female, and the average age was $32.28 \pm 12.64$. There was no statistically significant difference between the patient and control groups in terms of age, gender, economic status, marital status, occupation, and education.

BAI, BDI, GAD-7, PSWQ, MCQ-30 total and subscale, and GADS-R total and subscale scores were found to be statistically higher in the patients with GAD compared to a healthy control group (all $\mathrm{p}$ values were smaller than 0.001 ) except the MCQ-30 positive beliefs subscale ( $\mathrm{p}=0.759)$ (Table 2 ).

\section{Item characteristics}

For each item, means, mean values, group mean differences, item-total correlation, and Cronbach Alpha if item deleted values are presented in Table 3 . The corrected item-total correlations of all items of the scale were above 0.331 , and these correlations were statistically significant. Cronbach Alpha if item deleted values ranged between 0.911 to 0.916 . Mean item scores of all participants ranged from 18.46 to 63.11 . Mean item scores of patients with GAD ranged from 26.14 to 76.32 and healthy controls ranged from 10.20 to 61.93 in GADS-R. The comparison of the mean of each item between the patient and the healthy group showed statistical significance except for five items (These were item 3.3, item 3.9, item 5.8, item 5.10, and item 5.12).

\section{Factor analyses}

The principal components analysis was performed for a total of 28 GADS- $R$ items. Based on the original scale, the factor analysis of Varimax rotation revealed that there are five factors with eigenvalues above 1 which define $65.3 \%$ of the variance. The KMO value for the 28 items scale was 0.866 , supporting the use of factor analysis in the whole sample. Bartlett's sphericity test, the suitability of the data for factor analysis was statistically significant $\left(\chi^{2}=5611.975, \mathrm{df}=378, \mathrm{p}<0.001\right)$. Table 4 shows the factor loadings. The factors load ranged from 0.304 to 0.704 . All items showed a factor load of 0.38 and were considered in the analysis.

\section{Reliability analysis}

Cronbach's alpha coefficient determined the internal consistency of the 28-item GADS-R, and it was calculated, yielding a reliability estimate of 0.916 for the scale. These results indicated that GADS-R total score has high internal consistency. Cronbach's alpha coefficient was also calculated for each of the five subscales. The coefficient a was 0.819 and 0.802 for the severity and frequency of worry, range 0.578 to 0.811 for the coping strategies, range 0.605 to 0.789 for the avoidance of worry, range 0.393 to 0.840 for the negative metacognitive

Table 1. Sociodemographic characteristics of participants

\begin{tabular}{|c|c|c|c|c|c|}
\hline & Total participant $(\mathrm{N}=312)$ & Patients with GAD $(\mathrm{N}=114)$ & Healthy controls $(\mathrm{N}=198)$ & $\mathrm{T} / \chi^{2}$ value & p value \\
\hline Sex & & & & $1.793^{*}$ & 0.181 \\
\hline Female & $185(59.3)$ & $62(54.4)$ & $123(62.1)$ & & \\
\hline Male & $127(40.7)$ & $52(45.6)$ & $75(37.9)$ & & \\
\hline Age (yr) & $32.28 \pm 12.64$ & $32.20 \pm 12.41$ & $32.32 \pm 12.80$ & $0.078^{\dagger}$ & 0.938 \\
\hline Education & & & & $1.149^{*}$ & 0.563 \\
\hline Primary school & $43(13.8)$ & $18(15.8)$ & $25(12.6)$ & & \\
\hline High school & $195(62.5)$ & $67(58.8)$ & $128(64.6)$ & & \\
\hline University & $74(23.7)$ & $29(25.4)$ & $45(22.7)$ & & \\
\hline Marital status & & & & $0.188^{*}$ & 0.664 \\
\hline Married & $102(32.7)$ & $75(65.8)$ & $135(68.2)$ & & \\
\hline Single & $210(67.3)$ & $39(34.2)$ & $63(31.8)$ & & \\
\hline Income & & & & $4.664^{*}$ & 0.097 \\
\hline Low & $68(21.8)$ & $21(18.4)$ & $47(23.7)$ & & \\
\hline Middle & $100(32.1)$ & $45(39.5)$ & $55(27.8)$ & & \\
\hline High & $144(46.2)$ & $48(42.1)$ & $96(48.5)$ & & \\
\hline Occupation & & & & $0.018^{*}$ & 0.892 \\
\hline Employed & $212(67.9)$ & $78(68.4)$ & $134(67.7)$ & & \\
\hline Unemployed & $100(32.1)$ & $36(31.6)$ & $64(32.3)$ & & \\
\hline
\end{tabular}

Data are presented as mean \pm standard deviation or N (\%). ${ }^{*}$ chi-squre test; ${ }^{\dagger}$ studen $t$ test. GAD, Generalized Anxiety Disorder 
Table 2. Comparison of the scale scores between the Generalized Anxiety Disorder (GAD) patients and healthy control group

\begin{tabular}{|c|c|c|c|c|}
\hline & Patients with GAD (N=114) & Controls $(\mathrm{N}=198)$ & T value & $\mathrm{p}$ value \\
\hline Beck Anxiety Inventory & $44.90 \pm 15.46$ & $5.91 \pm 6.05$ & $25.803^{*}$ & $<0.001^{\dagger}$ \\
\hline Beck Depression Inventory & $24.58 \pm 9.65$ & $3.86 \pm 4.17$ & $21.777^{*}$ & $<0.001^{\dagger}$ \\
\hline Generalized Anxiety Disorder-7 & $19.61 \pm 4.26$ & $2.68 \pm 2.59$ & $38.467^{*}$ & $<0.001^{\dagger}$ \\
\hline Penn-state Worry Questionnaire & $49.85 \pm 7.98$ & $35.72 \pm 9.26$ & $14.180^{*}$ & $<0.001^{\dagger}$ \\
\hline \multicolumn{5}{|l|}{ Metacognitions Questionnaire } \\
\hline Positive beliefs & $11.77 \pm 4.00$ & $11.62 \pm 4.27$ & $0.307^{*}$ & 0.759 \\
\hline Uncontrollability and danger & $15.76 \pm 4.00$ & $12.41 \pm 3.38$ & $7.865^{*}$ & $<0.001^{\dagger}$ \\
\hline Cognitive confidence & $14.67 \pm 4.74$ & $10.07 \pm 3.68$ & $8.921^{*}$ & $<0.001^{\dagger}$ \\
\hline Need to control thoughts & $18.46 \pm 3.10$ & $10.32 \pm 3.16$ & $22.036^{*}$ & $<0.001^{\dagger}$ \\
\hline Cognitive self-consciousness & $18.12 \pm 2.93$ & $15.72 \pm 4.31$ & $5.267^{*}$ & $<0.001^{\dagger}$ \\
\hline Total & $78.79 \pm 11.64$ & $60.16 \pm 11.92$ & $13.404^{*}$ & $<0.001^{\dagger}$ \\
\hline \multicolumn{5}{|c|}{ Turkish version of the Generalized Anxiety Disorder Scale-Revised } \\
\hline Severity & $136.51 \pm 39.25$ & $68.68 \pm 34.73$ & $15.828^{*}$ & $<0.001^{\dagger}$ \\
\hline Cope & $562.41 \pm 165.25$ & $422.09 \pm 195.42$ & $6.748^{*}$ & $<0.001^{\dagger}$ \\
\hline Avodance & $253.28 \pm 100.48$ & $127.84 \pm 80.21$ & $11.401^{*}$ & $<0.001^{\dagger}$ \\
\hline Negative metacognition & $374.07 \pm 132.52$ & $186.99 \pm 123.56$ & $12.539 *$ & $<0.001^{\dagger}$ \\
\hline Positive metacognition & $212.29 \pm 136.29$ & $133.83 \pm 116.20$ & $5.386^{*}$ & $<0.001^{\dagger}$ \\
\hline Total & $1544.71 \pm 381.17$ & $939.45 \pm 355.98$ & $14.090^{*}$ & $<0.001^{\dagger}$ \\
\hline
\end{tabular}

Data are presented as mean \pm standard deviation. ${ }^{*}$ student-t test; ${ }^{\dagger} \mathrm{p}<0.001$

beliefs, and range 0.384 to 0.866 for the positive metacognitive beliefs. These values suggest that the five subscales of the GADS-R had respectable internal consistency. Table 4 shows the Cronbach's alpha coefficient for total and subgroups in the full study population.

\section{Convergent validity}

To assess the content validity of GADS-R, the relationship between each item of GADSR (total and subgroups) and MCQ30 (total and subgroups), BDI, BAI, GAD-7, PSWQ was examined. Correlations between the clusters, and the total score of the GADS-R, and the MCQ-30 (total and subgroups), BDI, BAI, GAD-7, PSWQ are presented in Table 5 for the full study population.

\section{Cut-off value}

ROC curve was used to assess the sensitivity and specificity of our scale (AUC: 878 and 95\% CI: 0.840-916). The ROC curve is presented in Figure 1. According to our sample, the GADS-R appears to demonstrate relatively acceptable sensitivity and specificity for detecting anxiety disorders at a cut-off point of 1188 (sensitivity=86.8, specificity=76.8).

\section{DISCUSSION}

The most significant result of this study is that GADS-R is a valid and reliable questionnaire. Another critical part of this study is GADS- $\mathrm{R}$ is a multidimensional scale that can be used in both diagnosis and follow-up for anxiety disorders and examines the time engaged worrying, distress levels due to worrying, negative and positive metacognitive beliefs about worry and coping behaviors, types, and frequency of behaviors used to avoid and cope with worry and danger. ${ }^{15}$ To our knowledge, this is the first study in the literature that assesses the validity and reliability of the GADS-R.

Generalized anxiety disorder is a frequent mental health problem and comorbidity which has destructive effects on an individual's quality of life. There is a need for a questionnaire that assesses the dimensions and maintenance factors of the anxiety disorder. Planned study with this aim showed that patients with an anxiety disorder had significantly higher BAI, BDI, GAD-7- PSWQ, GADS-R total, and subscale, MCQ-30 total, and subscale scores except for positive beliefs in MCQ30. There was a statistically significant difference between anxiety patients and the control group in the GADS-R positive metacognitive subscale which may be due to GADS- $\mathrm{R}$ is specifically developed as a disorder-specific scale when compared to MCQ-30 for GAD.

Comparison of GADS-R item scores showed that mean item scores of patients with GAD ranged from 26.14 to 76.32 and healthy controls ranged from 10.20 to 61.93 , in which all reached significant statistical difference except for five items. 
Table 3. Item characteristics of the GADS-R

\begin{tabular}{|c|c|c|c|c|c|c|c|}
\hline & $\begin{array}{l}\text { Total participant } \\
\text { GADS-R Score }\end{array}$ & $\begin{array}{c}\text { Patients with } \\
\text { Anxiety Disorder } \\
\text { GADS-R Score }\end{array}$ & $\begin{array}{c}\text { Controls } \\
\text { GADS-R Score }\end{array}$ & T value & $\mathrm{p}$ value & $\begin{array}{l}\text { Corrected } \\
\text { item-total } \\
\text { correlation } \\
\end{array}$ & $\begin{array}{c}\text { Cronbach } \\
\text { alpha if item } \\
\text { deleted } \\
\end{array}$ \\
\hline Item 1 & $47.24 \pm 24.93$ & $68.09 \pm 20.30$ & $35.23 \pm 18.67$ & 14.497 & $<0.001^{\dagger}$ & $0.622^{\dagger}$ & 0.912 \\
\hline Item 2 & $46.23 \pm 25.67$ & $68.42 \pm 22.38$ & $33.46 \pm 17.43$ & 14.355 & $<0.001^{\dagger}$ & $0.632^{\dagger}$ & 0.912 \\
\hline \multicolumn{8}{|l|}{ Item 3} \\
\hline Item 3.1 & $47.72 \pm 27.82$ & $61.18 \pm 24.29$ & $39.96 \pm 26.79$ & 6.966 & $<0.001^{\dagger}$ & $0.592^{\dagger}$ & 0.912 \\
\hline Item 3.2 & $54.93 \pm 28.55$ & $65.24 \pm 25.75$ & $48.99 \pm 28.45$ & 5.027 & $<0.001^{\dagger}$ & $0.572^{\dagger}$ & 0.913 \\
\hline Item 3.3 & $63.11 \pm 29.81$ & $65.15 \pm 28.73$ & $61.93 \pm 30.41$ & 0.919 & 0.359 & $0.415^{\dagger}$ & 0.915 \\
\hline Item 3.4 & $54.85 \pm 31.22$ & $70.39 \pm 27.03$ & $45.90 \pm 29.98$ & 7.403 & $<0.001^{\dagger}$ & $0.648^{\dagger}$ & 0.911 \\
\hline Item 3.5 & $50.00 \pm 31.95$ & $63.49 \pm 31.25$ & $42.23 \pm 29.75$ & 5.963 & $<0.001^{\dagger}$ & $0.517^{\dagger}$ & 0.913 \\
\hline Item 3.6 & $51.76 \pm 30.02$ & $66.45 \pm 26.67$ & $43.31 \pm 28.60$ & 7.051 & $<0.001^{\dagger}$ & $0.522^{\dagger}$ & 0.913 \\
\hline Item 3.7 & $39.78 \pm 28.93$ & $50.88 \pm 30.56$ & $33.40 \pm 25.96$ & 5.133 & $<0.001^{\dagger}$ & $0.605^{\dagger}$ & 0.912 \\
\hline Item 3.8 & $54.57 \pm 29.90$ & $60.20 \pm 28.97$ & $51.33 \pm 30.02$ & 2.545 & $0.011^{*}$ & $0.518^{\dagger}$ & 0.913 \\
\hline Item 3.9 & $56.65 \pm 33.06$ & $59.43 \pm 32.82$ & $55.05 \pm 33.17$ & 1.127 & 0.261 & $0.383^{\dagger}$ & 0.916 \\
\hline \multicolumn{8}{|l|}{ Item 4} \\
\hline Item 4.1 & $31.61 \pm 27.06$ & $45.29 \pm 31.39$ & $23.74 \pm 20.50$ & 6.566 & $<0.001^{\dagger}$ & $0.382^{\dagger}$ & 0.915 \\
\hline Item 4.2 & $32.93 \pm 26.56$ & $49.01 \pm 27.98$ & $23.67 \pm 20.71$ & 8.430 & $<0.001^{\dagger}$ & $0.474^{\dagger}$ & 0.914 \\
\hline Item 4.3 & $40.18 \pm 29.31$ & $59.98 \pm 30.62$ & $28.79 \pm 21.48$ & 9.599 & $<0.001^{\dagger}$ & $0.594^{\dagger}$ & 0.912 \\
\hline Item 4.4 & $36.46 \pm 28.93$ & $54.50 \pm 27.28$ & $26.07 \pm 24.44$ & 9.199 & $<0.001^{\dagger}$ & $0.549^{\dagger}$ & 0.913 \\
\hline Item 4.5 & $32.49 \pm 28.12$ & $44.52 \pm 29.13$ & $25.57 \pm 25.10$ & 5.812 & $<0.001^{\dagger}$ & $0.464^{\dagger}$ & 0.914 \\
\hline \multicolumn{8}{|l|}{ Item 5} \\
\hline Item 5.1 & $30.56 \pm 33.72$ & $56.80 \pm 33.47$ & $15.45 \pm 22.92$ & 11.701 & $<0.001^{\dagger}$ & $0.603^{\dagger}$ & 0.912 \\
\hline Item 5.2 & $43.14 \pm 32.49$ & $50.88 \pm 32.71$ & $38.69 \pm 31.59$ & 3.240 & $0.001^{\dagger}$ & $0.377^{\dagger}$ & 0.916 \\
\hline Item 5.3 & $56.68 \pm 32.00$ & $70.96 \pm 28.24$ & $48.46 \pm 31.20$ & 6.520 & $<0.001^{\dagger}$ & $0.479^{\dagger}$ & 0.914 \\
\hline Item 5.4 & $55.96 \pm 35.69$ & $76.32 \pm 26.34$ & $44.24 \pm 35.15$ & 9.135 & $<0.001^{\dagger}$ & $0.571^{\dagger}$ & 0.913 \\
\hline Item 5.5 & $32.72 \pm 36.19$ & $71.84 \pm 27.89$ & $10.20 \pm 15.04$ & 21.837 & $<0.001^{\dagger}$ & $0.656^{\dagger}$ & 0.911 \\
\hline Item 5.6 & $36.28 \pm 32.97$ & $47.28 \pm 31.15$ & $29.95 \pm 32.39$ & 4.615 & $<0.001^{\dagger}$ & $0.483^{\dagger}$ & 0.914 \\
\hline Item 5.7 & $39.62 \pm 33.52$ & $64.91 \pm 32.81$ & $25.05 \pm 23.94$ & 11.348 & $<0.001^{\dagger}$ & $0.615^{\dagger}$ & 0.912 \\
\hline Item 5.8 & $30.41 \pm 26.96$ & $33.04 \pm 28.18$ & $28.89 \pm 26.19$ & 1.312 & 0.190 & $0.331^{\dagger}$ & 0.916 \\
\hline Item 5.9 & $24.70 \pm 26.30$ & $35.83 \pm 31.26$ & $18.28 \pm 20.45$ & -5.368 & $<0.001^{\dagger}$ & $0.460^{\dagger}$ & 0.914 \\
\hline Item 5.10 & $25.54 \pm 26.80$ & $28.51 \pm 30.80$ & $23.84 \pm 24.12$ & 1.391 & 0.166 & $0.350^{\dagger}$ & 0.916 \\
\hline Item 5.11 & $18.46 \pm 24.64$ & $23.86 \pm 27.53$ & $15.35 \pm 22.29$ & 2.810 & $0.005^{\dagger}$ & $0.441^{\dagger}$ & 0.915 \\
\hline Item 5.12 & $23.78 \pm 25.92$ & $26.14 \pm 28.70$ & $22.42 \pm 24.14$ & 1.165 & 0.245 & $0.371^{\dagger}$ & 0.916 \\
\hline
\end{tabular}

Data are presented as mean \pm standard deviation. ${ }^{*} \mathrm{p}<0.05 ;{ }^{\dagger} \mathrm{p}<0.01$. GADS-R, Generalized Anxiety Disorder Scale-Revised

In the coping subscale, tried to reason things out (item 3.3) and planned how to cope if my worries were true (item 3.9) had no significance between control and GAD. Additionally, in the positive metacognitive belief subscale If I worry I will be prepared (item 5.8), worrying helps me get things done (item 5.10) and worrying helps me solve problems (item 5.12) did not reach a significant difference. All of the five items were about the usefulness of the worry and coping worry with more thinking which might increase engagement in worrying. These results might be due to these strategies might often be used by healthy control in Turkish culture, and a healthy population also might have positive metacognitive beliefs regarding worrying. However, the healthy control group might stop it whenever they want due to the lack of negative metacognitions and did not find worrying dangerous, so they do not develop GAD according to the metacognitive theory. Additionally, worrying helps me cope (item 5.7), worrying keeps me safe (item 5.9), something bad that would happen if I did not worry (item 5.11) might be more associated with the disorder.

The reliability was calculated by the Cronbach Alpha In- 
Table 4. Factor loadings and Cronbach's Alpha coefficient of the scale in full study population

\begin{tabular}{|c|c|c|c|c|c|c|}
\hline & \multicolumn{5}{|c|}{ The Turkish version of the Generalized Anxiety Disorder Scale-Revised } & \multirow[b]{2}{*}{$\begin{array}{c}\text { Total } \\
\text { factor loadings }\end{array}$} \\
\hline & $\begin{array}{c}\text { Severity and } \\
\text { frequency of worry } \\
\text { factor loadings }\end{array}$ & $\begin{array}{l}\text { The coping } \\
\text { strategies } \\
\text { factor loadings }\end{array}$ & $\begin{array}{c}\text { Deal and avoidance } \\
\text { of worry } \\
\text { factor loadings }\end{array}$ & $\begin{array}{c}\text { Negative } \\
\text { metacognitive beliefs } \\
\text { factor loadings }\end{array}$ & $\begin{array}{c}\text { Positive } \\
\text { metacognitive beliefs } \\
\text { factor loadings }\end{array}$ & \\
\hline Item 1 & 0.819 & & & & & 0.697 \\
\hline Item 2 & 0.802 & & & & & 0.704 \\
\hline Item 3.1 & & 0.578 & & & & 0.654 \\
\hline Item 3.2 & & 0.771 & & & & 0.630 \\
\hline Item 3.3 & & 0.811 & & & & 0.460 \\
\hline Item 3.4 & & 0.675 & & & & 0.702 \\
\hline Item 3.5 & & 0.584 & & & & 0.570 \\
\hline Item 3.6 & & 0.577 & & & & 0.591 \\
\hline Item 3.7 & & 0.641 & & & & 0.650 \\
\hline Item 3.8 & & 0.745 & & & & 0.556 \\
\hline Item 3.9 & & 0.711 & & & & 0.425 \\
\hline Item 4.1 & & & 0.648 & & & 0.436 \\
\hline Item 4.2 & & & 0.605 & & & 0.528 \\
\hline Item 4.3 & & & 0.710 & & & 0.652 \\
\hline Item 4.4 & & & 0.785 & & & 0.609 \\
\hline Item 4.5 & & & 0.789 & & & 0.521 \\
\hline Item 5.1 & & & & 0.479 & & 0.658 \\
\hline Item 5.2 & & & & 0.779 & & 0.421 \\
\hline Item 5.3 & & & & 0.840 & & 0.511 \\
\hline Item 5.4 & & & & 0.817 & & 0.601 \\
\hline Item 5.5 & & & & 0.393 & & 0.713 \\
\hline Item 5.6 & & & & 0.674 & & 0.512 \\
\hline Item 5.7 & & & & & 0.384 & 0.659 \\
\hline Item 5.8 & & & & & 0.696 & 0.348 \\
\hline Item 5.9 & & & & & 0.834 & 0.473 \\
\hline Item 5.10 & & & & & 0.926 & 0.357 \\
\hline Item 5.11 & & & & & 0.852 & 0.446 \\
\hline Item 5.12 & & & & & 0.866 & 0.377 \\
\hline Self-value & 3.436 & 4.569 & 3.190 & 3.182 & 3.904 & 8.884 \\
\hline Variance $(\%)$ & 12.27 & 16.31 & 11.39 & 11.39 & 13.94 & 31.730 \\
\hline Cumulative (\%) & 12.27 & 28.58 & 39.97 & 51.36 & 65.30 & 31.730 \\
\hline Cronbach's Alpha & 0.930 & 0.887 & 0.820 & 0.858 & 0.874 & 0.916 \\
\hline
\end{tabular}

ternal Consistency Coefficient (CAICC). A minimum of 0.70 CAICC was necessary to achieve internal consistency. ${ }^{22}$ The 28-item GADS-R's Cronbach's alpha coefficient was 0.916 and Cronbach Alpha if item deleted values ranged from 0.911 to 0.916 .

Due to these results, the internal consistency of the GADS$\mathrm{R}$ Turkish version is high. Furthermore, five subscales of the GADS-R; severity and frequency of worry, coping strategies, avoidance from worry, negative metacognitive beliefs, and positive metacognitive beliefs have good internal consistency which means this scale can measure levels of these parameters separately. As a result of these analyses, it has been seen that the unique five-factor structure of the scale is reliable in the Turkish language.

In the assessment of the content validity, total and subscales of GADS-R have a positive correlation with BDI, BAI, GAD-7, MCQ-30, and PSWQ. However, there was no correlation between GADSR 'severity and frequency of worry', 'coping strat- 


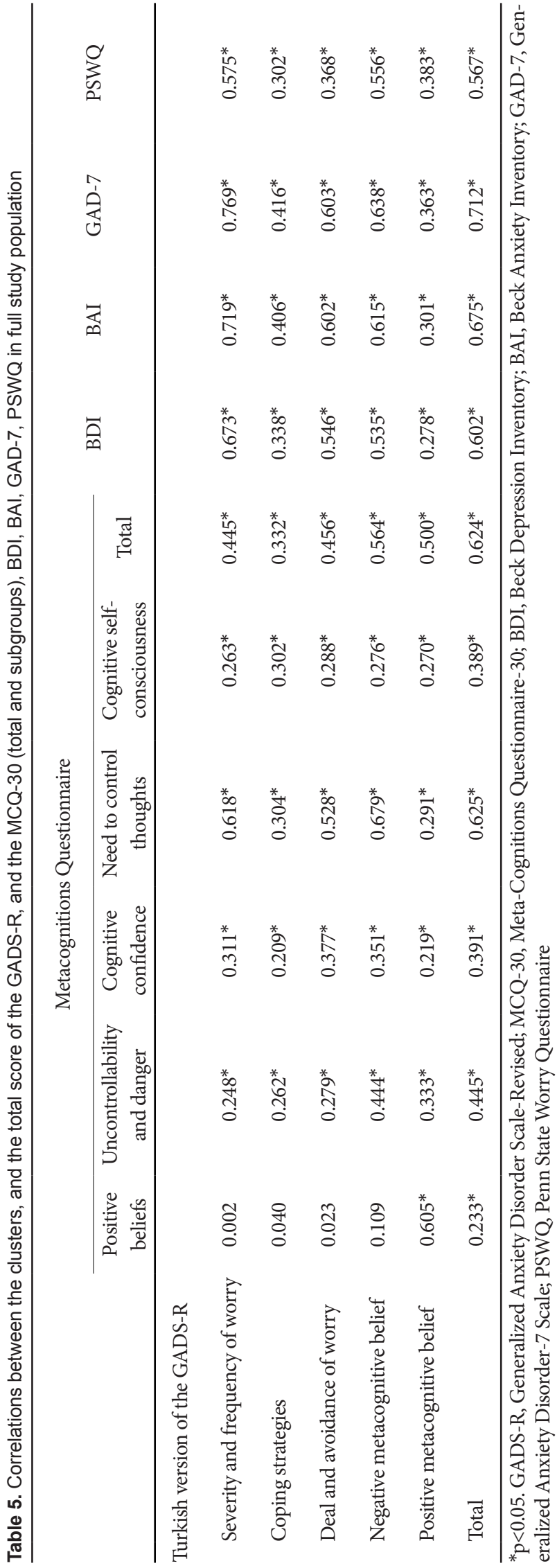

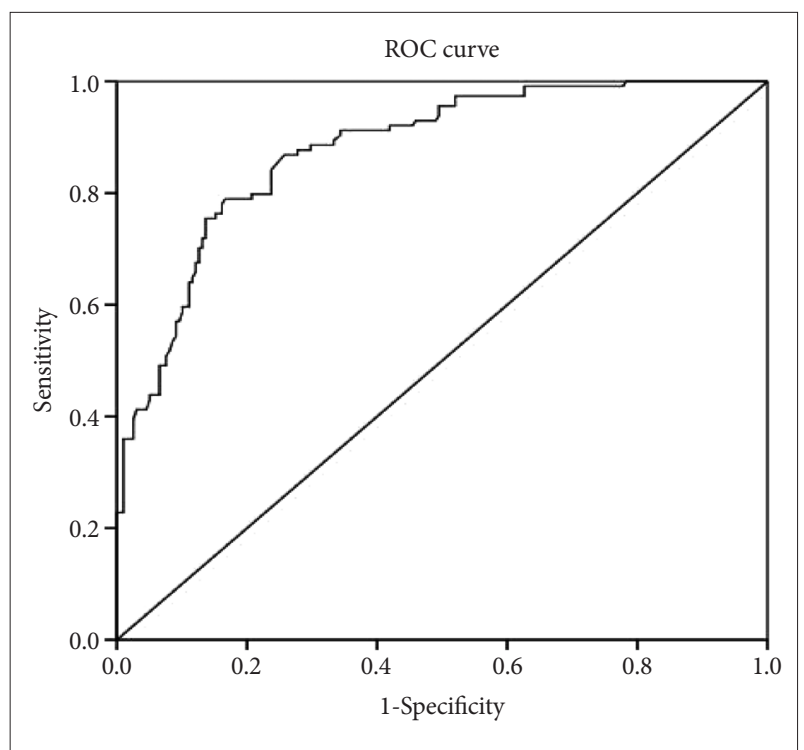

Figure 1. Receiver operating characteristic (ROC) curve for GADS$R$ for diagnoses of generalized anxiety disorders (AUC: 878 and 95\% Cl: 0.840-916). GADS-R, Generalized Anxiety Disorder ScaleRevised; $\mathrm{AUC}$, area under the curve; $\mathrm{Cl}$, confidence interval.

egies,' 'avoidance from worry', and 'negative metacognitive beliefs' subscales and MCQ-30 positive belief subscales. These results may be due to psychopathology is strongly associated with negative metacognitive beliefs, and without negative metacognitive beliefs there GAD would not be present since the metacognitive model of the GAD suggests that GAD develops when negative meta-beliefs are formed and activated as mentioned earlier. These results imply that the content validity of GADS- $\mathrm{R}$ is high.

Values lower than 0.3 for the KMO imply that the data set is not well suited for factor analysis ${ }^{23}$ and our $\mathrm{KMO}$ value for the 28 items scale was 0.866 , supporting the use of factor analysis in this sample. Exploratory factor analysis with Varimax rotation was performed to examine the validity of the factor structure of GADS-R in the Turkish sample which showed $65.3 \%$ of the variance was defined by five factors with eigenvalues above one and ranged between 3.18 to 4.56 . Additionally, the total factor load was 0.38 , and factor loads of subscales ranged from 0.304 to 0.704 which shows the construct validity of the scale in the Turkish language.

All of the item scores converted between $0-100$ to assess the cut-off point. Sensitivity and specificity of our scale assessed via ROC curve and had found a cut-off point of 1,188 with $86.8 \%$ sensitivity and $76.8 \%$ specificities for distinguishing anxiety disorder from those who do not meet diagnostic criteria

To sum up, these results showed that the validity, reliability, and cut-off scores of the GADS-R Turkish version. GADS-R is a unique scale that assesses assess time engaged in worrying, 
distress levels due to worrying, negative and positive metacognitive beliefs about worry and coping behaviors, types and frequency of behaviors used to avoid and cope with worry and danger.

\section{Availability of Data and Material}

The datasets generated or analyzed during the study are available from the corresponding author on reasonable request.

\section{Conflicts of Interest}

The authors have no potential conflicts of interest to disclose.

\section{Author Contributions}

Conceptualization: Anıl Gündüz, Sencan Sertçelik, Alişan Burak Yaşar, Arif Çipil, Elvan Başak Usta Gündüz. Data curation: İbrahim Gündoğmuş, Betül Hacer Engin, Hatice Gönül, Elvan Başak Usta Gündüz. Formal analysis: Anıl Gündüz, Aysel İşler, Hatice Gönül, Elvan Başak Usta Gündüz. Funding acquisition: Sencan Sertçelik, Betül Hacer Engin, Arif Çipil, Elvan Başak Usta Gündüz. Investigation: Anıl Gündüz, Sencan Sertçelik, Alişan Burak Yaşar, Hatice Gönül, Arif Çipil, Elvan Başak Usta Gündüz. Methodology: Anıl Gündüz, İbrahim Gündoğmuş, Sencan Sertçelik, Betül Hacer Engin, Aysel İşler, Alişan Burak Yaşar. Project administration: Anıl Gündüz, İbrahim Gündoğmuş, Alişan Burak Yaşar, Hatice Gönül, Arif Çipil, Elvan Başak Usta Gündüz. Resources: Anıl Gündüz, İbrahim Gündoğmuş, Sencan Sertçelik, Betül Hacer Engin, Aysel İşler, Alişan Burak Yaşar. Software: İbrahim Gündoğmuş, Aysel İşler, Arif Çipil, Elvan Başak Usta Gündüz. Supervision: Anıl Gündüz, İbrahim Gündoğmuş, Alişan Burak Yaşar, Hatice Gönül, Arif Çipil. Validation: İbrahim Gündoğmuş, Sencan Sertçelik, Aysel İșler, Elvan Başak Usta Gündüz. Visualization: İbrahim Gündoğmuş, Aysel İşler, Alişan Burak Yaşar, Hatice Gönül, Arif Çipil. Writing-original draft: Anıl Gündüz, İbrahim Gündoğmuş, Elvan Başak Usta Gündüz. Writing-review \& editing: Anıl Gündüz, İbrahim Gündoğmuş, Sencan Sertçelik, Betül Hacer Engin, Aysel İşler, Alişan Burak Yaşar, Hatice Gönül, Arif Çipil, Elvan Başak Usta Gündüz.

\section{ORCID iDs}

Anıl Gündüz

İbrahim Gündoğmuş

Sencan Sertçelik

Betül Hacer Engin

Aysel İşler

Alişan Burak Yaşar

Hatice Gönül

Arif Çipil

Elvan Bașak Usta Gündüz

https://orcid.org/0000-0002-5159-238X https://orcid.org/0000-0002-1921-1495 https://orcid.org/0000-0002-4880-074X https://orcid.org/0000-0002-9353-4292 https://orcid.org/0000-0002-1373-9969 https://orcid.org/0000-0002-6778-3009 https://orcid.org/0000-0002-0204-4600 https://orcid.org/0000-0002-9569-6789 https://orcid.org/0000-0002-3883-1964

\section{Funding Statement}

None

\section{Acknowledgments}

We thank participants.

\section{REFERENCES}

1. American Psychiatric Association. Diagnostic and Statistical Manual of Mental Disorders (DSM-5 $5^{\circ}$ ). Washington DC: American Psychiatric Pub; 2013 .

2. Haller H, Cramer H, Lauche R, Gass F, Dobos GJ. The prevalence and burden of subthreshold generalized anxiety disorder: a systematic re- view. BMC Psychiatry 2014;14:128.

3. Wittchen HU, Kessler RC, Beesdo K, Krause P, Höfler M, Hoyer J. Generalized anxiety and depression in primary care: prevalence, recognition, and management. J Clin Psychiatry 2002;63(Suppl 8):24-34.

4. Wells A, King P. Metacognitive therapy for generalized anxiety disorder: An open trial. J Behav Ther Exp Psychiatry 2006;37:206-212.

5. Gündüz A, Gündoğmus İ, Sertçelik S, Engin BH, İşler A, Çipil A, et al. Validity and reliability of cognitive attentional syndrome-1 questionnaire. Psychiatry Investig 2019;16:355-362.

6. Normann N, van Emmerik AA, Morina N. The efficacy of metacognitive therapy for anxiety and depression: A meta-analytic review. Depress Anxiety 2014;31:402-411.

7. Wells A, Welford M, King P, Papageorgiou C, Wisely J, Mendel E. A pilot randomized trial of metacognitive therapy vs applied relaxation in the treatment of adults with generalized anxiety disorder. Behav Res Ther 2010;48:429-434.

8. Wells A. Advances in metacognitive therapy. Int J Cogn Ther 2013;6: 186-201.

9. Olatunji BO, Wolitzky-Taylor KB, Sawchuk CN, Ciesielski BG. Worry and the anxiety disorders: a meta-analytic synthesis of specificity to GAD. Appl Prevent Psychol 2010;14:1-24.

10. Wells A, Papageorgiou C. Relationships between worry, obsessive-compulsive symptoms and meta-cognitive beliefs. Behav Res Ther 1998;36: 899-913.

11. Boysan M, Keskin S, Beşiroğlu L. Assessment of hierarchical factor structure, reliability and validity of penn state worry questionnaire turkish version. Klinik Psikofarmakoloji Bülteni-Bull Clin Psychopharmacol 2008;18:174-182.

12. Hisli-Sahin N. A study on the validity of Beck Depression Inventory. Turk Psikoloji Dergisi 1988;6:118-126

13. Tosun A, Irak M. Adaptation, validity, and reliability of the metacognition questionnaire-30 for the Turkish population, and its relationship to anxiety and obsessive-compulsive symptoms. Turk Psikiyatri Dergisi 2008; 19:67-80.

14. Konkan R, Senormancı O, Guclu O, Aydin E, Sungur M. Validity and reliability study for the Turkish adaptation of the Generalized Anxiety Disorder-7 (GAD-7) scale. Arch Neuropsychiatry 2013;50:53-58.

15. Wells A. Metacognitive Therapy for Anxiety and Depression. New York: Guilford Press; 2011.

16. Wells A, Cartwright-Hatton S. A short form of the metacognitions questionnaire: properties of the MCQ-30. Behav Res Ther 2004;42:385396.

17. Beck AT, Steer RA. Internal consistencies of the original and revised Beck Depression Inventory. J Clin Psychol 1984;40:1365-1367.

18. Beck AT, Epstein N, Brown G, Steer RA. An inventory for measuring clinical anxiety: Psychometric properties. J Consult Clin Psychol 1988; 56:893-897.

19. Ulusoy M, Şahin NH, Erkmen H. Turkish version of the Beck Anxiety Inventory: Psychometric properties. J Cognit Psychother 1996;12:163172.

20. Jordan P, Shedden-Mora MC, Loew B. Psychometric analysis of the Generalized Anxiety Disorder scale (GAD-7) in primary care using modern item response theory. PLoS One 2017;12:e0182162.

21. Meyer TJ, Miller ML, Metzger RL, Borkovec TD. Development and validation of the penn state worry questionnaire. Behav Res Ther 1990; 28:487-495.

22. Tezbaşaran AA. Likert tipi ölcek geliştirme kılavuzu. İstanbul: Turk Psikologlar Derneği Yayınları; 1997

23. Thompson B. Exploratory and Confirmatory Factor Analysis. Washington, DC: American Psychological Association; 2004. 